\title{
Genetic Determinism and the Innate-Acquired Distinction in Medicine
}

\author{
Maria E. Kronfeldner
}

Received: 26 September 2008/ Accepted: 8 July 2009/Published online: 10 September 2009

(C) The Author(s) 2009. This article is published with open access at Springerlink.com

\begin{abstract}
This article illustrates in which sense genetic determinism is still part of the contemporary interactionist consensus in medicine. Three dimensions of this consensus are discussed: kinds of causes, a continuum of traits ranging from monogenetic diseases to car accidents, and different kinds of determination due to different norms of reaction. On this basis, this article explicates in which sense the interactionist consensus presupposes the innate-acquired distinction. After a descriptive Part 1, Part 2 reviews why the innate-acquired distinction is under attack in contemporary philosophy of biology. Three arguments are then presented to provide a limited and pragmatic defense of the distinction: an epistemic, a conceptual, and a historical argument. If interpreted in a certain manner, and if the pragmatic goals of prevention and treatment (ideally specifying what medicine and health care is all about) are taken into account, then the innate-acquired distinction can be a useful epistemic tool. It can help, first, to understand that genetic determination does not mean fatalism, and, second, to maintain a system of checks and balances in the continuing nature-nurture debates.
\end{abstract}

M. E. Kronfeldner ( $\square)$

Abteilung Philosophie, Universität Bielefeld,

33051 Bielefeld, Germany

e-mail: mkronfeldner@uni-bielefeld.de
Keywords Genetic determinism . Innate-acquired distinction - Geneticization · Genetic disease - Medicine $\cdot$ Norm of reaction . Parity thesis · Fatalism

Whether or not specific diseases are considered as innate is of utmost importance, in science as well as in society. The design of research projects as well as public health programs depend on the answers that are given. Moreover, private health insurance companies believe that so-called genetic information would be incredibly useful to discriminate against those who have costly genetic diseases. The existence of genetic information nondiscrimination legislature indicates that those who want to prevent these companies from getting such information seem to share the same belief in the value of the information, i.e., that genes tell you something about you and your destiny.

This belief in the value of genetic information indicates that in contemporary science and society there exists a specific form of genetic determinism, or to be more precise a tendency to believe in kinds of genetic determination. How does this tendency come about? This article aims to illustrate that it strongly relies on the deeply entrenched innate-acquired distinction, which rests on the pragmatics of medicine and health care. Whether it makes sense to follow this tendency depends on the case in point and on choices that have more to do with society than with science. 
Thus, after illustrating the contemporary interactionist consensus and the tenacity of the innateacquired distinction in a descriptive Part 1, I shall briefly portray in Part 2 the battlefield of whether we would do better to get rid of the bipolar innateacquired distinction. This leads to a limited and preliminary defense of the bipolar frame from a pragmatic point of view.

\section{The Interactionist Consensus and the Tenacity of the Innate-Acquired Distinction}

If today a disease is called innate, this usually means that it is genetic. ${ }^{1}$ The predicate "is genetic" is, however, not meant ontologically: diseases are not genes and they are not in the genes. To have a genetic disease is meant causally: the disease is caused by genes and is in this sense genetically determined. But what does that mean? Almost all researchers in the life sciences would admit that genes alone do not determine or cause anything. They are not acting in isolation. In this sense, everybody is an interactionist. Everybody believes that traits of organisms are always caused by genes and environment. New findings in epigenetics (or epigenomics) currently boost this interactionist consensus, but the consensus emerged independently of these new findings and does not change in the face of them, ${ }^{2}$ and neither does the following. The interactionist consensus assumes a dichotomous (i.e., exhaustive and exclusive) partitioning of factors: there are genes (i.e., specific bits of DNA) and there are environmental factors (i.e., everything except the DNA). Nonetheless, a dichotomous partitioning of traits into innate versus acquired traits (i.e., either caused by genes or by environment) is excluded simply because any trait is always caused by genes and environment.

Despite this consensus that there are no traits that are caused either by genes or by environment, the number of those diseases that are counted as genetic

\footnotetext{
${ }^{1}$ Innateness can be (and has in the past also been) used in a broader sense, allowing epigenetic influences to be innate as well. However, it seems that the concept of innateness is now mainly used in the narrow, i.e., genetic, sense just described. For the history of the concept of innateness, see the references in footnote 11 .

${ }^{2}$ See Jablonka and Lamb (1995) and Gilbert and Epel (2009) on epigenetics.
}

diseases increases constantly. ${ }^{3}$ I take Hedgecoe's (2001) term enlightened geneticization to refer to such a seemingly paradoxical situation: nobody believes in genetic determinism, but the number of diseases that are counted as genetic continues to grow. Are scientists contradicting themselves? Do they simply pay lip service to interactionism, while actually being biased towards genetic determinism? I think they do neither. This paradox disappears when we look at different kinds of what we can mean by calling something a cause, and if we look at the pragmatics of why we mean one thing and not the other.

\section{Kinds of Causes}

That genes alone cannot cause anything simply means that they are never sufficient to bring about the respective effect. Nonetheless, they might well be either necessary conditions for the occurrence of a specific trait or count as probabilistic causes of a specific trait. If something is a necessary condition of a trait, most are prepared to call it a cause of that trait. Many would also admit that it makes sense to call something a cause of a trait if there is strong statistical evidence for the causal significance of a factor, as in sentences such as "smoking causes cancer." If a defect in a specific gene locus is taken to be a necessary condition for a disease (as, for instance, the gene for Huntington chorea called huntingtin, located on chromosome 4 p16.3) or taken to be a probabilistic cause, we call the disease genetic, and say that the (defect in the) gene causes it. However, as long as these kinds of causes are not sufficient, we hesitate to say that they bring about the trait, or cause the trait; and how could they, if they are not sufficient to do so? If there were purely genetically determined traits, given this way of framing the debate, then genes would be sufficient conditions of these traits. It follows from the sheer fact of development that there cannot be any of these purely genetically determined traits.

\footnotetext{
${ }^{3}$ Lemke (2007, p. 158) has reported that the number of those diseases included as genetic in the online database Online Mendelian Inheritance in Man (OMIM; 2000) doubled from 1992 to 1998 , i.e., from approximately 5,000 to approximately 10,000. It has again doubled since then: on May 9, 2009, the OMIM counts 19,436 genetic diseases.
} 
It equally follows from the sheer fact of development that there are no traits that are completely undetermined by genetic factors. Traits we usually consider as acquired (as, for instance, the capacity to write a scientific article) are also not caused by acquired factors alone. On the contrary, lots of genes are necessary to make it possible. Furthermore, the situation that something is called a cause even though it is not sufficient for the effect is not specific to genes. The same is true for infectious diseases, which are often described as being caused by viruses, bacteria or other pathogenic biotic agents, in the same way as genetic diseases are described as being caused by (defects in) genes. However, if genetic diseases are-strictly speaking-not caused, i.e., brought about, by genes, then infectious diseases are not caused by pathogenic agents either. They are not caused by pathogenic agents since these pathogenic agents are never sufficient conditions. In both cases, lots of other conditions, which also play a causal role in the generation of a trait, hover in the background. In science, these background conditions are stuffed into ceteris paribus clauses since they are not of interest, for reasons depending on the context.

In the case of a complete account of genetic determination, it would be necessary to analyze the involved concepts of causation in much more detail. Such a detailed account is neither possible nor intended here. ${ }^{4}$ The aim herein is more moderate and the strategy is similar to compatibilist discussions of free will. These discussions proceed more often than not without a clear concept of causation. At issue here is not freedom, but hope. Is the hope of human beings for prevention and treatment of diseases compatible with genetic determination? An important basic step for answering this question is to illustrate what genetic determination means.

The distinction between kinds of causes (i.e., sufficient conditions, necessary conditions, probabilistic causes) is a first step in that direction and it resolves the alleged paradox of enlightened geneticization: when we call a disease genetic, we talk about

\footnotetext{
$\overline{4}$ Gannett (1999) provides a pragmatic account of the reasons why genes are usually in the foreground and is a useful starting point for an account of the concept of causation involved in geneticization. Compare Wendler (1996) and Waters (2007).
}

the existence of a factor (i.e., a necessary condition or a statistically correlated one), even though we would acknowledge (if pressed) that this is not the whole causal story. When we talk about genetic determination, we do not make a claim about genes as sufficient conditions of a trait. However, if genes are not sufficient for bringing about diseases, why are patients (and those who care for them) so interested in genes? The reasons are pragmatic.

\section{Preventing and Bringing About}

The difference between looking for necessary conditions and looking for sufficient conditions mirrors the difference between aiming to prevent and aiming to bring about something. If we want to prevent something, then we look for a necessary condition and, if possible, eliminate the potential cause. If we want, for instance, to prevent malaria, then we try to prevent a mosquito bite, even though the mosquito bite is certainly not sufficient for malaria. ${ }^{5}$ If we want to prevent something, then looking for sufficient conditions is ineffective, and unnecessary. ${ }^{6}$ If a mosquito bite is a necessary condition for malaria, then preventing it is sufficient for preventing malaria. We look for sufficient conditions only if we want to cause something, e.g. if we want to bring about a malarial infection in someone. Statistical causes can be treated as being relevant for both preventing and bringing about something, since knowledge about them can be used for both goals. Diseases are things we usually want to prevent, and the clinical context of medicine as well as public health care are ideally defined by the pragmatic goal of prevention (and treatment, if the former is not possible anymore).

The described pragmatic frame explains why we often do not look for sufficient conditions in medicine, but it does not explain why we focus on a specific sort of potential necessary conditions, namely genes. It does not explain why genes are considered the most promising candidates when we

\footnotetext{
5 See, for instance, Skyrms (2000, pp. 69-70) for this connection between pragmatic goals and conditions.

6 The same holds for remote necessary conditions, such as the beginning of life on Earth etc.
} 
search for causes. We could also focus our search on whether specific environments are necessary conditions for specific diseases, but we often do not. According to Gannett (1999), the increasing bias towards genes is due to a higher epistemic (and technological) tractability in experimentation. In addition, as she says, this tractability "fits well with the traditional North American approach to medicine which, in its assumption of a biological and reductionist model of disease, focuses on internal, rather than external, factors in pathogenesis" (Gannett 1999, p. 359). We look for causes that we can handle, i.e., control. Today, we strongly believe that we can handle genes easily, now that we are able to experiment on them, map them, screen them, and select them via abortion and preimplantation genetic diagnosis technology. We believe this even though gene therapy and pharmacogenetics are still more a promise (or spectre) than a reality. Indeed, we believe in genes since we can now do things with them that we cannot do as easily with environments. Try to screen your personal environment the way we screen DNA: it is impossible. At least as long as we do not know which environmental aspect to focus on, environmental factors are harder to grasp epistemically and technologically. Kitcher attributes this situation to the "fragility of our representation of the non-genetic causal factors" (Kitcher 2003, p. 289). However, it is not only the possibilities of representation that differ. The genome is complex, but compared with the multitude of factors making up all the rest, i.e., the environment influencing development, the genome is rather simple. The bits of DNA floating around in our body might still be harder to change in a goal-directed manner, but epistemically these bits have become much more tractable than environmental factors, which are easy to handle only if known to be relevant. We might well come closer day by day to the knowledge and technology necessary for the dystopia of eugenics, but we are as far as ever from Skinner's (1948) behaviorist dystopia of "Walden Two," i.e., designing society by controlling the environment.

Despite these brief remarks, a full account of why we concentrate so much on genes has to wait for another occasion. The story goes much deeper: into epistemological, ontological, anthropological, ethical, as well as historical matters. However, the aim here is simply to make explicit in which sense interactionism goes together with the increase of genetic diseases. The answer is: genes are increasingly taken to be easily tractable causes (necessary conditions or probabilistic causes) of diseases.

\section{The Continuum of Traits and In-Principle Debates}

Even though the interactionist consensus does not assume that there is a dichotomous partitioning between innate and acquired traits, as illustrated above, it does assume that there is a continuum of traits with two poles: ranging from monogenetic diseases, such as Huntington chorea or phenylketonuria, to largely acquired impairments, such as the loss of an arm due to a car accident. In between these poles, the realm of complexity reigns: many genes interact with each other and with environmental factors in complex ways. Scientific progress in this area is still quite tentative. ${ }^{7}$

If we sort diseases along this simple continuum, we already refuse to take part in any debates that ask whether genes are in principle more determining than other factors. Debates over whether genes act as informational, or programming, or have any other property that makes them special, vivid until today in philosophy of biology, become pointless from this perspective. First of all, whether genes are more determining than other factors depends on the case in point and is a matter of degree. Second, the interactionist consensus (i.e., that genes are never sufficient conditions and that there is a continuum of traits) will not change, irrespective of which side of such inprinciple debates we end up with. Third, nobody in medicine is interested in an answer to in-principle debates. The patients as well as the physicians want to know where on the continuum a disease resides and whether it is possible to prevent it, but they do not want an answer to one of the in-principle debates. This is understandable, since only the former questions touch the issue of fatalism, an important issue, if prevention is one of your goals. In-principle debates only tackle philosophical in-house problems about ontology, causation, information, and so on:

\footnotetext{
7 See Schaffner (2006) for a useful introduction to the current state of the art in molecular methods and other older tools, such as twin studies.
} 


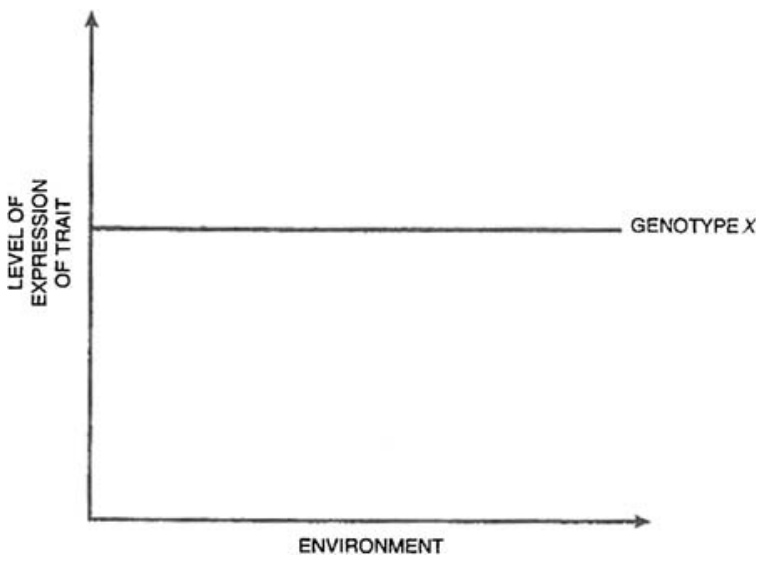

Fig. 1 A (hypothetical) flat norm of reaction (Kitcher 2003, p. 285)

important topics, certainly, but not for the patient or physician.

Norms of Reaction and Kinds of Determination

In addition to the continuum, and partly constituting it, the interactionist consensus rests on a further nondichotomizing way of putting the issue: genes have specific norms of reaction that differ in various ways, defining the kind of determination at issue. Norms of reaction have been used for almost 100 years. ${ }^{8}$ They are very useful in depicting the role of nurture. Figure 1 shows the simplest form of a norm of a reaction. It has a flat form.

Such a flat norm of reaction shows that changes in the value of the environmental variable (horizontal axis) do not make a difference to the level of expression of a trait (vertical axis), given a specific genotype. Kitcher regards such a flat norm of reaction as "[a] graphical representation of the simplest type of genetic determinism." As Fig. 2 illustrates, there are further "deterministic themes," i.e., kinds of genetic determination, correlated with other shapes of the norms of reaction.

A flat norm of reaction means that the level of expression for a trait is constant across all the measured environments. The other kinds of genetic determination also express kinds of constancy. As Kitcher (2003, p. 286) explains: "[i]n (a), the level of

\footnotetext{
$\overline{8}$ See Falk (2001) on the history of the concept.
}

expression of the trait is constant (for genotype $\mathrm{X}$ ) in almost all environments; in (b), the level of expression is almost constant across all environments, in (c), despite variation in levels associated with genotypes $\mathrm{X}$ and $\mathrm{Y}$, the level of expression for individuals with $\mathrm{X}$ is always greater than that for $\mathrm{Y}$, no matter what the environment, in (d), there is considerable variation in the level of expression but only in environments that are unhealthy." These kinds of genetic determination "admit further refinements, combinations, and variations," as Kitcher continues. That they all exhibit forms of constancy justifies Kitcher's grouping of them together as kinds of genetic determination.

An example should suffice to illustrate why mentioning these kinds of genetic determination is important. Fukuyama, in his Our Posthuman Future, says that the word "nature," as in "human nature," does not imply "rigid genetic determination" (Fukuyama 2002, pp. 130-133). With this, he wants, as everybody today, to escape the charge of ignoring nurture. After introducing the bell curve for human height as an example, and after admitting that average height increased from the Middle Ages until today in all the groups of people he considers, thanks to "economic development and improved nutrition," he concludes that, nonetheless, "the average male-female differences are the products of heredity and thus nature." $\mathrm{He}$ thus ends up with nature only. In order to illustrate explicitly why he does so is intriguing. Fukuyama not only assumes the determinist theme (c), but he also changes, in between, the explanandum. He started with the individual level of development of the token trait height and ends with talking about the interindividual level of differences in the expression of this trait as a type. This change, inscribed in any move from a developmental context to norms of reaction, is not illegitimate, but it is important to make clear what the move means, since it includes not only a change from an individual to an interindividual level, but also a change of explanandum, and thus a change in the type of answer, and probably a change in the concept of causation involved (e.g., from causes as developmental resources to causes as difference makers). Finally, the move includes a change of perspectivefrom looking at the complex developmental process to looking at simple correlations between genotypes and phenotypes. It is a change to a perspective that black-boxes the developmental process. When we do 
Fig. 2 Deterministic themes (Kitcher 2003, p. 285)
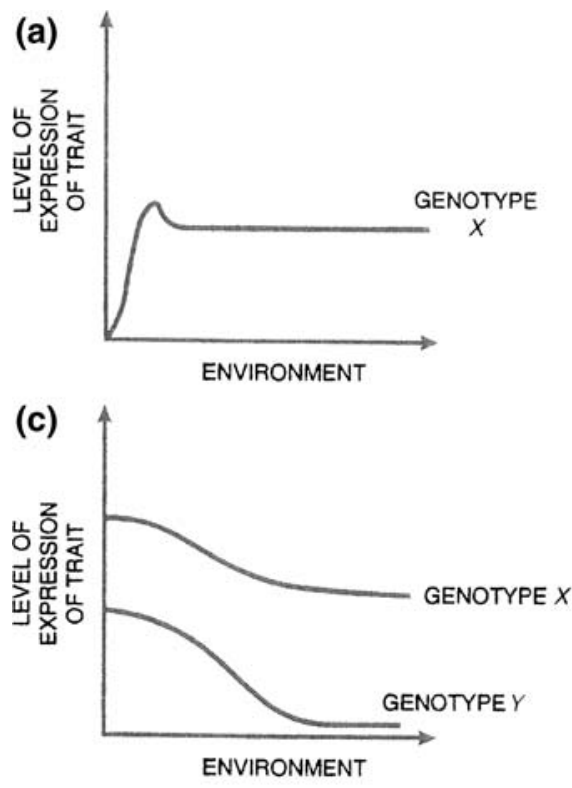
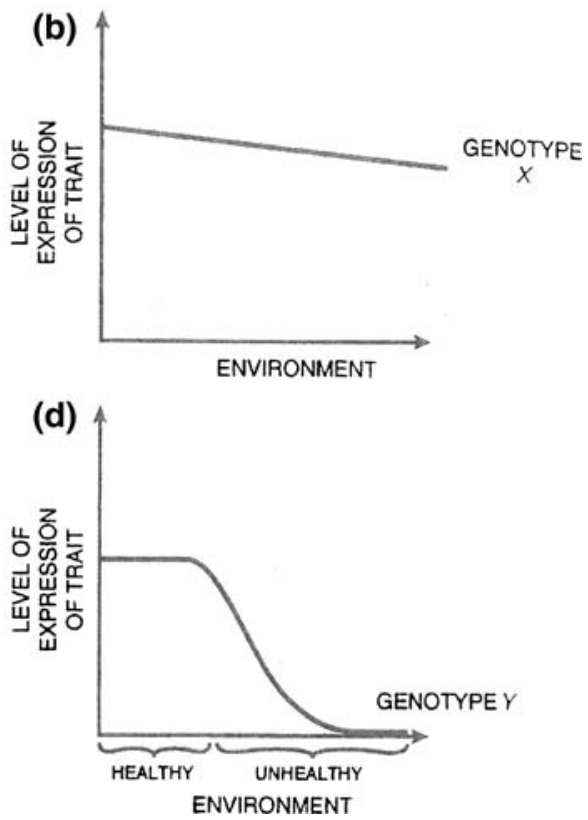

not have means to understand the complex actual developmental process, we look at the termini only, as Kitcher (1996, p. 242) says. In order to investigate genotype-phenotype correlations, plotting a norm of reaction, despite its simplifying nature, is nonetheless fruitful, at least for practical contexts such as medicine, as, for instance, Lewontin (1985, pp. 114-122) and Kitcher (2003, pp. 285-286) argue.

The concept of norms of reaction shows, as the simple continuum view already did, that the naturenurture issue is a matter of degree and that the answers depend on the case in point. In-principle debates are out of place. A norm of reaction also allows us to clearly distinguish between the different kinds of genetic determination depicted by Kitcher, something we could not do if we only had a simple continuum. Knowing the norm of reaction for a trait, given a specific gene, is thus much more informative than locating a disease at a certain position on the simple continuum.

In addition, a norm of reaction clearly shows how society determines whether a trait is considered as innate (i.e., genetically determined) or not. Each genotype has a specific and context-dependent norm of reaction, specific for each gene and dependent on a given range of environments. Extrapolation to and thus prediction of the expression of the trait in environments not covered in the norm of reaction is not possible. This point, stressed already by Hogben (1933) and pushed again forcefully by Lewontin (1985), adds another dimension to the case dependency already evident in the continuum view. There simply is no general answer to whether genes or environmental factors are more important. It depends not only on the trait but also on the environments considered. Whether a gene determines (in one of the above-mentioned ways) a specific trait depends on the environments we single out for consideration. Since it will always be hard to epistemically single out the most relevant environments, the value of a norm of reaction is limited, as Kitcher (2003, pp. 288-291) states, even though, as illustrated, a norm of reaction is more informative than simply placing a disease on the simple continuum. Since it is our society that determines which environments are available at all for consideration, our society strongly influences whether a trait is considered as genetically determined or not. As long as we do not provide equal education, for instance, we will not be able to make a reliable statement about the development of individuals in such an equal environment.

Last but not least, that norms of reaction can take different shapes illustrates that genetic determination does not always support fatalism. Something can be genetically determined, even if it can be prevented from occurring. Phenylketonuria (PKU) seems to be 
the single most often-cited example for this in the literature on genetic determinism. It is conventionally treated as a monogenetic disorder. As Huntington chorea, it is at the hereditary extreme of the continuum of traits, with severe effects on neural development, among other things. Today, all newborns are screened for PKU, at least in Europe and the USA. The disorder is held to be genetic/genetically determined, even though the ailments caused by having a genetic defect for PKU can usually be prevented, if one manages to exclude the amino acid phenylalanine from the diet. The norm of reaction is not flat, but punctuated, as in Kitcher's determinist theme (a).

Even if the case of PKU shows that no fatalism is implied in our talk of genetic diseases, the just-given picture of PKU is still a simplified one. There is a considerable amount of clinical heterogeneity (i.e., same mutation with different disease patterns) and of genetic heterogeneity in PKU (i.e., different mutations with same clinical pattern). ${ }^{9}$ The actual norm of reaction of PKU would very likely be not only punctuated, but a bit fuzzy: because of the two kinds of heterogeneity, because of genotype-genotype interaction (epistasis), and because of complex genotype-phenotype interaction. The more knowledge we get, the more complex the picture of the etiology and nature of PKU becomes. However, the point I want to make here is independent of these complications, since the simple as well as the complex picture support the point about the difference between genetic determination and fatalism, and that is the important point in this article. In addition, the complex picture seems not to disturb the bias towards geneticization. Despite the possibility of prevention, and despite heterogeneity, the disease is held to be genetic/genetically determined. There are three obvious reasons (and certainly other less obvious ones) why PKU is still held to be genetic/

\footnotetext{
${ }^{9}$ See Kaplan (2000, pp. 13-21) and Lindee (2006) on the history and pitfalls of the making of PKU as a genetic disease. See Wolf (1997) for an overview of genetic and clinical heterogeneity in a variety of diseases (such as cystic fibrosis, Huntington disease as well as PKU, to name but a few), challenging the idea of monogenetic diseases.
}

genetically determined. There is a gene, the $P A H$ gene, at which mutations correlated with PKU have been identified; there is relative developmental stability over a specific range of environments; and the physiological mechanism is understood quite well.

$\mathrm{Be}$ that as it may, PKU is a telling example for this study, since it shows how society enters the connection between genetic determination and fatalism. In a possible world that does, contrary to our world, not allow for any environment without phenylalanine, PKU would probably have a flat norm of reaction. It would be a fatal destiny. However, the following also holds, and that is the important aspect. If we currently regard a genetic disease, or such Mendelian traits as sex or blood group, as having a flat norm of reaction, we might ignore a socially possible world, in which a different set of environments would destroy the flatness of the norm of reaction and allow modification of the trait. The untried possible worlds are always bountiful. If they are untried, we should not forget to ask who gains by leaving them untried. The important conclusion from considering norms of reaction as part of our interactionist consensus is thus: whatever the scientific, and often mere statistical, measure with which we try to express that environment does not influence a trait (be it Mendelian segregation, a flat norm of reaction, positive predictive value, penetrance, heritability, expressivity, concordance rate, etc.), it is a measure that is context dependent. It is dependent on the environments considered in the measure. Which environments are considered is a choice, and the choice depends on which environments are considered as practically possible and desirable in this world. It depends on our socially determined preferences about how the world should look, especially with respect to war, crime, poverty, education, and so on.

The Three Dimensions of the Consensus and the Innate-Acquired Distinction

It is time to summarize the account of interactionism given here: a rigid genetic determinism has largely been replaced by an interactionist consensus. This consensus nonetheless embraces the above-mentioned deterministic themes, i.e., kinds of determination. The innate-acquired distinction appears in a nondichotomous, nongeneralizing, and nonfatalistic manner: first, there is no dichotomous partitioning of 
traits but a continuum of traits, ranging from genetic diseases to acquired traits; second, where we put a trait along this axis cannot be generalized since it depends on the environments considered; finally, if a disease such as PKU is considered as a genetic disease, it does not imply fatalism. In sum, there is no simple dichotomy between innate and acquired traits in our contemporary interactionist concept of genetic determination. At the level of causal factors (rather than traits), however, we have a very clearcut partitioning, as the concept of norms of reaction shows, which depends on the exclusive and exhaustive distinction between genetic factors on the one hand and nongenetic factors on the other. As mentioned in the beginning, the nongenetic factors include everything except DNA (i.e., epigenetic and other cellular factors, physical environment, education, society, culture, and so on).

The interactionist consensus, with its three conceptual levels (i.e., necessary conditions or statistical factors, continuum of traits, and norms of reactions), is thus not sufficient to get rid of the age-old divide between nature and nurture. This is also mirrored in the practical context of treatment of diseases as well as in our folk concept of innateness. The innateacquired distinction is quite tenacious, at least in medicine.

\section{The Practical Context of Treatment}

Lewontin et al. (1984, p. 7), in their now classic Not in our Genes, wrote that biological determinism includes biologized treatment. According to them, treatment of (allegedly) genetically determined diseases is reached either by (1) elimination of "undesirable genes (eugenics, genetic engineering, etc.)," by (2) "specific drugs (magic bullets)," to get rid of the biochemical and behavioral abnormalities, or by (3) "environmental intervention." Lewontin et al. claim that usually treatment is biologized (via the first and second kinds of treatment), and that only lip service is paid to the third kind of treatment.

Taking the latter for granted, it is not clear (at least not to me) why drugs count as biologized treatment and why environmental treatments do not. The boundary between the second and third kinds of treatment (drugs and environmental intervention, respectively) is fuzzy. The boundary between the first, i.e., genetic treatment, and the latter two is, however, clearcut, indeed very clearcut. Giving someone a pill is surely a different treatment than introducing a diet, as in the case of the genetic disorder PKU, and it certainly makes a difference for our vision of health whether we choose the second or the third kind of treatment, but what exactly accounts for the difference between them seems to be not very clear, at least not to me. The difference between giving a pill and keeping a diet on the one hand and eliminating the respective allele on the other hand, is, however, very clear: one is eliminating bits of DNA, the other is eliminating or changing the usual consequences of these hereditary factors by changing other factors. The clearcut dichotomous distinction between factors, which we found already inscribed in the norms of reaction, is thus reappearing in the context of treatment. Furthermore, it is also constitutive for the concept of innateness, a concept that has recently been at issue in a vivid debate in the philosophy of biology.

\section{The Folk Concept of Innateness}

A review of the current debate about the concept of innateness lists "twenty-six candidates for [a] scientific successor to the folk concept of innateness" (Mameli and Bateson 2006, p. 177). Each of the finalists of these candidates refers to only one aspect of the complex and fuzzy folk concept of innateness, e.g., present at birth, reliably appearing during a specific stage of the lifecycle, not possible or not easy to change by environmental manipulation, developmentally canalized, generatively entrenched, speciestypical, etc. I cannot go into the details of the debate. Space would not suffice to do so, and it is not necessary for the purpose of this article. ${ }^{10} \mathrm{I}$ intend merely to reconstruct the contemporary folk concept of innateness, and to do so only with respect to those aspects that are relevant for understanding the concept of genetic determination in medicine. I thus regard the following as a good approximation of the folk concept of innateness:

\footnotetext{
$\overline{10}$ Some of the candidates do not rely on an innate-acquired distinction, such as the concept of generative entrenchment, suggested by Wimsatt $(1986,1999)$, or canalization, suggested by Ariew (1999).
} 
$\mathrm{X}$ is innate if and only if it is present at the moment of birth (or, if that is not the case, at least inevitably appearing during development at a certain age, relative to a given range of environments), and does so because of causal factors present at the moment of conception.

Let me briefly justify this reconstruction, which is a revised version of Stich's dispositional account of innateness (Stich 1975): With "if it is present at the moment of birth" genes themselves and congenital diseases are certified to be innate. Since there are diseases that are usually regarded as innate but are not present at the moment of birth, we need the phrase "at least inevitably appearing during development." With this addition, the definition applies to standard cases of hereditary dispositions, such as PKU, which are not present at birth. The phrase "relative to a given range of environments" is needed since innate dispositions such as PKU are not inevitable occurring in all possible environments, but only relative to a given range of environments, namely all the environments in which phenylalanine is part of nutrition. With the phrase "because of causal factors present at the moment of conception," the definition excludes standard cases of acquired diseases (or acquired dispositions for diseases).

The exclusion of acquired diseases is part of the folk concept of innateness, and this is the important point for this article. Wendler and Ariew made this explicit with their claim that there are diseases associated with biotic agents that are regularly acquired in the normal course of one's development but not considered as innate. Their example is the acquisition of the bacterium Clostridium difficile ( $C$. diff.) (Wendler 1996, pp. 93-96; Ariew 1999, p. 133). Humans normally get clostridia via nutrition, without negative effects. When, however, sick people are treated with antibiotics, then $C$. diff. may cause diarrhea and other symptoms. Usually, the reaction to such an example is that such infectious dispositions should be excluded from being innate, even though they are, relative to a specific set of environments, inevitably acquired during development. Without the addition of the phrase "because of causal factors present at the moment of conception" to our approximation of the folk concept of innateness, we would not be able to exclude such cases.
Certainly, this folk concept has a history and could be further questioned philosophically. The brief account just given will neither satisfy the historian nor the usual demands of philosophers with enough perseverance for infinite conceptual analysis. Many aspects of the situation I described were certainly different in the past and are certainly different in many other contexts in which the innate-acquired distinction is used as well. ${ }^{11}$ One would certainly find contexts in medicine, historical as well as contemporary, where there is no such clear bipolar distinction between genetic versus environmental factors or innate versus acquired dispositions. However, I merely claim that there are contexts in which there is such a clear division: the conceptual context of the interactionist consensus, the practical context of treatment, and the conceptual context of the folk concept of innateness. This holds even if there are other contexts where there is no such division.

Philosophers, on the other hand, would object that the above reconstruction fails. Given the reconstruction, we still can, in fact, count the possession of $C$. diff. as innate. Our interactionist consensus enables us to see that it is always genes (with stress on the plural) and environmental factors that are involved in the development of a specific trait. Thus, the acquisition of $C$. diff. also happens because of causal factors present at the moment of conception: it is because of a genotype that leads to phenotypes that ingest food and water that we acquire clostridia. If we had different genes, e.g., Martian or plant genes, then we might not acquire them. "In response," as Wendler writes, "one wants to say that even if we grant that changes in the human genotype would result in our not eating and drinking and, hence, not possessing clostridia, the fact that I possess clostridia, say, is environmental" (Wendler 1996, p. 93). I cannot here offer a final solution to whether we should, or how we could, consistently distinguish between innate and acquired diseases, given our interactionist consensus. As already mentioned in Part 1, such a solution would require a clear account of what causation in developmental contexts means

\footnotetext{
11 See Lomax (1977), Olby (1993), Gaudillière and Löwy (2001), and López-Beltrán (2007) on the history of the divide in medicine.
} 
and whether the individual is the level of analysis that we should concentrate on. ${ }^{12}$

The tentative reconstruction of the folk concept of innateness was merely intended to show that we intuitively want the definition of innateness to reflect a rigid innate-acquired distinction. In other words, our implicit assumption seems to be that there are two kinds of diseases: innate and acquired ones. This is not in contradiction to the continuum view. On the contrary, it is the foundation for it, defining the poles of the nondichotomous distinction. The continuum view only adds the realm of complexity for the cases in between the two extremes. In other words, we want to distinguish between diseases such as PKU and things like car accidents, despite the interactionist consensus. And we accept that there are myriads of cases that are hard to classify. In other words, we accept that the bipolar distinction between innate and acquired is vague. We accept this as we accept that the bipolar distinction between white and black is vague, i.e., allowing for myriad cases of color that are neither black nor white or with respect to which it is hard to tell whether they are black or white.

\section{Summary}

The practical context has shown that we assume there are two kinds of treatments and thus two kinds of causal factors; the two conceptual contexts have shown that, based on the exclusive distinction of causal factors (i.e., those present at the moment of conception versus others), our folk ontology still tends to sort traits into a bipolar scheme of innate versus acquired diseases. The bipolar scheme does, however, not assume two exclusive groups of diseases, since, if pressed, we admit the continuum of traits, despite the bipolar framing. All this shows the deep entrenchment of the innate-acquired distinction. However, this entrenchment certainly did not prevent philosophers from criticizing the distinction. Let us thus enter the minefield of whether one should use the innate-acquired distinction. What follows will not do away with the pitfalls in this minefield, but it will provide a specific perspective for dealing with it and some preliminary arguments in the direction of this perspective.

\footnotetext{
12 See Wendler (1996) instead, or Gannett (1999) and Waters (2007) for possible solutions.
}

\section{The Value of the Innate-Acquired Distinction}

\section{Constructive Interactionism}

Constructive interactionists (or transinteractionists) like Oyama $(1985,2000,2001)$ want to establish a true causal parity of the factors involved in development. ${ }^{13}$ According to them, we are wrongly apportioning the complex interaction in development into two distinct sets of factors: genes and the rest-innate factors of development and acquired ones. ${ }^{14}$ They object to this partitioning of developmental factors, because it is biased in allowing us to give genes a certain priority over the other set of factors. It is important to be very clear about what is actually criticized by a call for causal parity.

There are two ways of giving causal priority to genes that are strawman-like, since nobody actually believes in the respective priority. The first strawman-like claim is that genes control or determine as necessary and sufficient conditions the occurrence of a certain trait. This claim addresses the level of ontogenetic development. Part 1 illustrated that a denial of this is part of the interactionist consensus. The second strawman-like claim addresses the level of phylogenetic evolution: the claim that genes are the only hereditary elements in life (i.e., the only elements that get reliably transmitted between generations). Nobody believes in this either. We know that cells and other organic matter as well as behavior or culture is equally transmitted down the generations, and the evidence for epigenetic inheritance reinforces this point of view.

\footnotetext{
${ }^{13}$ I take the label "transinteractionists" from Kitcher (2003), who mentions Lewontin, Oyama, and other developmental systems theorists. See, for instance, the collected manifesto of Oyama et al. (2001). Oyama herself established the term "constructive interactionism" (e.g., Oyama 2001) for her position.

14 Apportioning development into two distinct sets of factors is different from assigning to each of the distinct and dichotomously classified factors involved in development a separate causal impact. Unfortunately it is often not clear what exactly is at issue when the gene-environment distinction is attacked. Distinguishing between the two issues is important since one can approve the former without the latter. This article is only about the former; see Sober (1988) for the latter. Discussing the latter would again demand a detailed account of causation, which would far exceed the space available here.
} 
However, there is also a third prioritizing claim that is not strawman-like, namely the claim that only genes are informational entities and/or selected by natural selection for having this or that function in normal or healthy development, while other factors and entities are no such units of selection. This claim is related to the evolutionary and to the developmental level but distinct from and independent of the first two ways of alleged prioritizing. Whether (and in which sense) genes are the only informational entity and/or units of selection is still a hot debate in the contemporary philosophy of biology. I will neither discuss the pros and cons, nor take sides. It is an inprinciple debate, and, as stated above, whichever side we choose in these debates, it would not make a difference for the kinds of determination at issue here.

I want to focus on something narrower: whether we have to get rid of a bipolar partitioning to prevent prioritizing of genes as it is actually practiced in the contemporary hunt for disease genes. This goal requires analyzing whether the bipolar partitioning between genes and environment, which is at the basis of and inscribed in the interactionist consensus, violates causal parity. At issue is not the usefulness, for instance, of the norm of reaction as such, but whether the gene-environment distinction inscribed in the concept of norms of reaction is an example of a habit of the mind, an intellectual habit that deserves severe criticism, namely the entrenched custom to regard some influences in development as more equal than others, as Oyama $(1985,2001)$ has described it, with an allusion to George Orwell's Animal Farm.

The moment we partition developmental factors into two dichotomous groups of factors, we assume a very specific gene-organism-environment relationship, namely what Johnston (1987) calls gene-environment interaction and what Kitcher describes as "isolating certain properties for exploration of their causal impact, regarding the phenotype as the product of contributions from particular kinds of DNA sequences, on the one hand, and from everything else, on the other" (Kitcher 2003, p. 285). According to Johnston (1987, p. 149), whose declared enemies are the "dichotomous views of behavioural development that oppose learned and innate behaviour, or genetic and environmental determinants," genes simply do not interact with the environment; only the organism does. Consequently, the environment, with which the organisms interact, starts outside of them. Kitcher's environment is, however, "total;" it includes "everything outside the [genetic] locus (or loci) of interest" (Kitcher 2003, pp. 288-291). Kitcher, in other words, assumes a truly exhaustive and exclusive gene-environment distinction, i.e., a true dichotomy. Either something is an environmental factor or it is a genetic factor. Nothing can be both and there is no third option. Given this, the organism seems to disappear as a separate causal agency. The organism becomes a mere effect and thus appears only as an explanandum but not as part of the explanans. Given all this, Johnston surely has a point, at least according to our folk ontology for most entities of the biotic world, since these organisms are key agents in the developmental and evolutionary processes. However, Johnston merely excludes his enemy by definition. Whether genes interact with the environment depends on how you conceptualize environment, but defining it either way does not settle the issue of whether it makes sense to partition developmental factors dichotomously. Furthermore, partitioning life into genetic and environmental factors does not lead to organisms as mere effects, since an effect can certainly be a cause for something else (e.g., niche construction), as Kitcher (2003) already stressed.

Fausto-Sterling (2000) provides an example of a different route. She also criticizes gene-environment interaction as ill-guided. She does so by comparing it with a similar atomistic view in neurology: it is the developmental system itself (replacing the category of organism) that causes something, as it is the neuronal net, and not a specific neuron or some neurons somewhere in the brain, that causes something in the brain. This is what Oyama (2001, p. 178) means when she talks about a "distributed set of participants" that cannot be broken apart. The responses of singular neurons depend on the responses of others. However, all these pleas against atomism simply lead back to the problem of black-boxing the complex web of actual interactions during development. The atomism exists only in the simplified picture that we use and often have to use, due to the lack of anything else, and with which we obtain knowledge about the norm of reaction. The distributed set of participants in the complex developmental process is black-boxed in the search for knowledge about the norm of reaction. However, having such knowledge, which is knowledge about what makes a difference for prevention, is 
quite useful, even if knowledge about the complex developmental processes, black-boxed as they are, is still missing.

Trying to prevent something demands different tools than trying to understand complex holistic development. At one point, Oyama writes: “...if phenotypic characteristics arise only when sufficient interactants are present in the proper place and at the proper time, and if all these factors are therefore given comparable causal and formative significance, then defining heredity as the passing on of all developmental conditions, in whatever manner, is preferable to defining it by genetic information. This does not require any distinction between hereditary and acquired traits, or even between mostly hereditary and mostly acquired ones; all it requires is some degree of association of developmental influences" (Oyama 2000, p. 43). Well, this does not require it; other issues such as those standard in medicine or health care, might well. The developmental systems theory perspective might thus turn out to be quite useless for the pragmatics that define the clinical context of medicine and health care. First, it is not clear that we would always be equipped with better norms of reactions if we knew the whole complex developmental story. It might further our knowledge about norms of reaction, but it might also fail to do so. Second, in medicine, we often do not want to wait, if we can get some decent knowledge by blackboxing. In other words, we do not want a doctor to tell us that it is all distributed and immensely complex, if we need his/her help.

If we admit that black-boxing can be useful, as Oyama (2001, pp. 181-183) does herself, then we still did not make progress in assessing whether it is useful to assume two exclusive sets of factors, given the pragmatic goals involved in the endeavor.

\section{Towards a Limited Defense}

The following tentative arguments, certainly in need of further elaboration, shall provide a first approximation of a limited pragmatic defense of the innateacquired distinction in medicine. These arguments are independent of the critique just discussed. Even if it were correct that the bipolar distinction leads to simplifications of the causal picture of development, this cannot prove that this simplification is necessarily something we should despise. Simplicity is an epistemic value, and in the clinical context it might well be that it pays to accept some simplicity to have some handles for prevention and treatment.

The question I thus focus on is in which sense the concept of the norm of reaction, and the underlying bipolar partitioning of causes, helps us to see that not everything is fatalistically determined by genes, despite its causally simplifying nature. In other words, in which sense does the bipolar distinction help us in the solving of what Oyama has called "issues of incidence-frequency, predictability, inevitability" (Oyama 2001, p. 181), issues that are important, given the pragmatic goals of prevention and treatment.

\section{Epistemic Argument}

The first argument, an epistemic argument, relates to knowledge about specific diseases. Without ever distinguishing in a precise way between genetic and environmental factors, it would be hard to see, for instance, that the genetic disease PKU is genetically determined in a nonfatalistic sense, i.e., genetically determined in a sense that does not imply inevitable occurrence. We could not see, at least not as easily as we pretend to, the difference between a flat norm of reaction and a punctuated one, if we were not to use the distinction between genetic and environmental factors. ${ }^{15}$ Without the innate-acquired distinction, we could hardly see beyond the enlightened geneticization mentioned above: paying lip service to interactionism and the continuum view would be the only ways to express ourselves with respect to issues of incidence. If we want to prevent a disease and intelligently vary the environment, then we might find a preventive effect of one of the environments, i.e., we might find a punctuated norm of reaction. Thus, from the pragmatic point of view, holding genes constant and varying other factors is not a case of giving genes priority. The bipolar partitioning of factors inscribed in the concept of the norm of reaction is therefore quite helpful, if we want to stress

\footnotetext{
$\overline{15}$ This holds even if the diet for PKU was discovered earlier than the mutations correlated with the disease. Hence, it is not the case that molecular biology helped to find the treatment. It was the other way round: the knowledge of treatment helped to find the gene, as Kaplan (2000, pp. 13-21) illustrates.
} 
the importance of environment, e.g., for prevention of a specific disease.

This argument is similar to an early argument from Lehrman (1970). He is counted as one of the first critics of the innate-acquired distinction in the 20th century, directing his critique against Konrad Lorenz's distinction between innate versus learned behaviors. One of his points was that Lorenz's program is heuristically fruitless. Lorenz black-boxed development and concentrated on developmental stability. Finding stability is, however, according to Lehrman, less informative than finding difference, e.g., a difference in phenotype caused by a difference in an environmental variable. "[A]n experimental manipulation that causes a change in the behavioural outcome has thrown some light on the process by which the behaviour develops, while an experimental manipulation that fails to cause any change in the outcome has failed to throw light upon the nature of the processes leading to the outcome" (Lehrman 1970, p. 29). It is a general characteristic and "of the essence" of the experimental method "that an experiment cannot be regarded as making a contribution to the understanding of any problem unless the experimenter has succeeded in finding alternate treatments that have different effects upon the outcome" (Lehrman 1970, pp. 29-30). Even though he criticizes the distinction between innate and acquired traits, the distinction between innate and acquired factors (i.e., genetic versus environmental ones) is of heuristic value, since we might have problems with conceptualizing and finding developmental plasticity with experiments that are not constructed on the basis of a gene-environment distinction. The innate-acquired distinction thus has epistemic value in finding environmental factors that prevent diseases. Even though Lehrman (1970, p. 20) reminds his reader that he is (and was in his famous 1953 article) addressing the "value of the dichotomy itself," he uses the dichotomy himself to make his claim about the fruitfulness of the experimental method. However, he uses it only at the level of factors and criticizes it at the level of processes (maturation versus learning) and of traits (innate versus learned), and so do I.

\section{Conceptual Argument}

The second argument refers to the context of classification of diseases. Does the innate-acquired distinction have a heuristic value for this endeavor? When you erase a bipolar distinction from a system of classification, you create a more inclusive set of things. This creates two problems. First, given our contemporary bias towards declaring more and more diseases as genetic, the elimination of the polarity will certainly further this tendency. The innateacquired distinction constantly pulls against the contemporary bias towards calling diseases genetic. Second, erasing distinctions increases rather than decreases trivialization. The more general, i.e., the more inclusive, you make a classificatory category, the more trivial, i.e., the less informative, it becomes. In other words, the more you include in a class, the less it means when an element is included. You lose depth of vision, indeed you might even literally see less. Certainly, to keep the distinction, as a bipolar but nondichotomous one, should not deter us from trying to fill out the space between the poles with ever finer categories.

\section{Historical Argument}

The third argument says that historically the distinction was necessary to keep those very factors on the table that the critics of the distinction want to give parity to. When, at the beginning of the 20th century, American anthropology was in the process of becoming an academic discipline, Alfred L. Kroeber, one of the famous students of Franz Boas, used the opposition between nature and nurture in the form of heredity versus culture, to reach for anthropology disciplinary identity and autonomy from genetics, evolutionary theory, as well as psychology. He did so by creating an epistemic object-culture - that, as he thought, only anthropologists are able to study properly. His making of culture as a new epistemic object was similar to the making of genes, which were postulated in the beginning of genetics as hypothetical entities and epistemic objects that can only by studied by genetics, then the new primus inter pares among the biological disciplines. Kroeber claimed that it is only through Weismann's concept of inheritance, which excluded Lamarckian inheritance of acquired characteristics, that one can see the decoupling between biological evolution and cultural change. Decoupling nature from culture means in this case that culture can change without a correlated change in the innate characteristics of individuals. 
Culture can and did historically take off, so to say. Culture is in this sense autonomous and relies on a separate and parallel process of inheritance. This is what Kroeber meant by calling culture "superorganic" (Kroeber 1917). There are two systems of inheritance: non-Lamarckian biological inheritance and an autonomous cultural inheritance. Kroeber's case shows that the distinction has been used to enrich scientific ontology and as a regulative ideal for local unification, which includes constructing and securing disciplinary boundaries and creating a systematic coherent family of questions for cultural anthropology. ${ }^{16}$ Most important here, Kroeber's case illustrates that the innate-acquired distinction did not simply further (by itself) the historical predecessor of contemporary genetic determinism or any other view that gives genes priority over other factors. Historically, the innate-acquired distinction did not prevent parity of factors. Kroeber's case shows that the opposite is the case. The innate-acquired distinction furthered the most radical opposition to racism, the historical predecessor of genetic determinism. However, it has to be mentioned that the parity Kroeber helped to establish (i.e., that there are two separate systems of inheritance) was reached with a price. Developmental interactions were totally out of sight and thus black-boxed. However, as the subsequent history has shown, interaction was easily brought in again later. That both factors were on the table as distinctive factors, as distinctive epistemic categories, was a precondition for giving them equal importance, parity, not only in evolutionary terms (as systems of inheritance) but also in developmental terms (as causal factors in development).

\section{Conclusions}

In sum, the innate-acquired distinction helped to put and keep on the table those very factors to which critics of the distinction want to give parity to. It helped establish nongenetic factors as a new epistemic object (culture as a system of inheritance and change) and helped install a new discipline that is still considered as crucial to get closer to a more detailed understanding of at least some of the environmental

\footnotetext{
${ }^{16}$ For a detailed case study on Kroeber's boundary work between anthropology and biology, see Kronfeldner (2009).
}

factors influencing human development: those subsumed under cultural influences. History shows that the bipolar distinction was, so to say, similar to an epistemic ladder. Whether it is a Wittgensteinian ladder, a ladder that we now-after we have climbed it - should throw away, as some might press us to do, is another issue. However, as I indicated with the epistemic and the conceptual argument, I doubt that we should. It would not help us further, neither to establish causal parity, nor to understand why genetic determination does not mean fatalism, nor in actually finding means to prevent diseases.

Acknowledgements I am much indebted to Philip Kitcher, Francesca Merlin, Edna Suarez, Cor van der Weele, Dan Brooks and to the colleagues of the Max Planck Institute for the History of Science in Berlin, for their highly valuable comments and suggestions. This research has been funded by the Max Planck Institute for the History of Science (Berlin), as part of a Karl Schädler Postdoctoral Fellowship.

Open Access This article is distributed under the terms of the Creative Commons Attribution Noncommercial License which permits any noncommercial use, distribution, and reproduction in any medium, provided the original author(s) and source are credited.

\section{References}

Ariew, Andre. 1999. Innateness is canalization: In defense of a developmental account of innateness. In Where biology meets psychology: Philosophical essays, ed. V.G. Hardcastle, 117-138. Cambridge, MA: MIT Press.

Falk, Raphael. 2001. Can the norm of reaction save the gene concept? In Thinking about evolution: Historical, philosophical, and political perspectives, ed. R.S. Singh, 119-140. Cambridge: Cambridge University Press.

Fausto-Sterling, Anne. 2000. Sexing the body: Gender politics and the construction of sexuality. New York: Basic Books.

Fukuyama, Francis. 2002. Our posthuman future. New York: Farrar, Straus and Giroux.

Gannett, Lisa. 1999. What's in a cause? The pragmatic dimensions of genetic explanations. Biology and Philosophy 14: 349-374.

Gaudillière, Jean.-Paul, and Ilana Löwy, eds. 2001. Heredity and infection: The history of disease transmission. London: Routledge.

Gilbert, Scott F., and David Epel. 2009. Ecological developmental biology: Integrating epigenetics, medicine, and evolution. Sunderland, MA: Sinauer.

Hedgecoe, Adam. 2001. Schizophrenia and the narrative of enlightened geneticization. Social Studies of Science 31: 875-911.

Hogben, Lancelot. 1933. Nature and nurture. London: George Allen \& Unwin. 
Jablonka, Eva, and Marion Lamb. 1995. Epigenetic inheritance and evolution: The Lamarckian dimension. Oxford: Oxford University Press.

Johnston, Timothy D. 1987. The persistence of dichotomies in the study of behavioral development. Developmental Review 7: 149-182.

Kaplan, Jonathan M. 2000. The limits and lies of human genetic research. London: Routledge.

Kitcher, Philip. 1996. The lives to come: The genetic revolution and human possibilities. London: Penguin.

Kitcher, Philip. 2003. Battling the undead: How and (how not) to resist genetic determinism. In Mendel's mirror: Philosophical reflections on biology, ed. P. Kitcher, 283-300. Oxford: Oxford University Press.

Kroeber, Alfred L. 1917. The Superorganic. American Anthropologist 19: 163-213.

Kronfeldner, Maria E. 2009. If there is nothing beyond the organic ...: Heredity and culture at the boundaries of anthropology in the work of Alfred L. Kroeber. NTM Journal of the History of Science, Technology and Medicine 17: 107-133.

Lehrman, Daniel S. 1970. Semantic and conceptual issues in the nature-nurture problem. In Development and evolution of behavior: Essays in memory of T. C. Schneirla, ed. L.R. Aronson, E. Tobach, D.S. Lehrman, et al., 17-52. San Francisco: Freeman and Co.

Lemke, Thomas. 2007. Mutationen des Gendiskurses: Der genetische Determinismus nach dem Humangenomprojekt. In Gouvernementalität und Biopolitik, ed. T. Lemke, 149-172. Wiesbaden: VS Verlag für Sozialwissenschaften.

Lewontin, Richard C. 1985. The analysis of variance and the analysis of causes. In The dialectical biologist, ed. R. Levins and R. Lewontin, 109-122. Cambridge, MA: Harvard University Press.

Lewontin, Richard C., Steven P. Rose, and Leon J. Kamin. 1984. Not in our genes: Biology, ideology and human nature. New York: Pantheon.

Lindee, Susan. 2006. Phenylketonuria and the rise of public health genetics. In Moments of truth in genetic medicine, ed. S. Lindee, 28-57. Baltimore: The Johns Hopkins University Press.

Lomax, Elizabeth. 1977. Hereditary or acquired disease? Early nineteenth century debates on the cause of infantile scrofula and tuberculosis. Journal of the History of Medicine 32: 356-374.

López-Beltrán, Carlos. 2007. The medical origins of heredity. In Heredity produced: At the crossroads of biology, politics, and culture, 1500-1870, ed. S. Müller-Wille and H.-J. Rheinberger, 105-132. Cambridge, MA: MIT Press.

Mameli, Matteo, and Patrick Bateson. 2006. Innateness and the sciences. Biology and Philosophy 21: 155-188.
Online Mendelian Inheritance in Man, OMIM (TM). 2000. McKusick-Nathans Institute of Genetic Medicine, Johns Hopkins University (Baltimore, MD) and National Center for Biotechnology Information, National Library of Medicine (Bethesda, MD). Available at: http://www.ncbi. nlm.nih.gov/omim/.

Olby, Robert C. 1993. Constitutional and hereditary disorders. In Companion encyclopedia of the history of medicine, vol. 1, ed. W.F. Bynum and R. Porter, 412-437. London: Routledge.

Oyama, Susan. 1985. The ontogeny of information: Developmental systems and evolution. Cambridge: Cambridge University Press.

Oyama, Susan. 2000. Evolution's eye: A systems view of the biology-culture divide. Durham, NC: Duke University Press.

Oyama, Susan. 2001. Terms in tension: What do you do when all the good words are taken? In Cycles of contingency: Developmental systems and evolution, ed. S. Oyama, P. Griffiths, and R.D. Gray, 177-193. Cambridge, MA: MIT Press.

Oyama, Susan, Paul Griffiths, and Russell D. Gray, eds. 2001. Cycles of contingency: Developmental systems and evolution. Cambridge, MA: MIT Press.

Schaffner, Kenneth F. 2006. Behavior: Its nature and nurture. In Wrestling with behavioral genetics: Science, ethics, and public conversation, ed. E. Parens, A.R. Chapman, and N. Press, 3-73. Baltimore: The Johns Hopkins University Press.

Skinner, Burrhus F. 1948. Walden Two. New York: Macmillan.

Skyrms, Brian. 2000. Choice and chance: An introduction to inductive logic, 4th edn. Stamford, CT: Wadsworth.

Stich, Stephen P. 1975. The idea of innateness. In Innate ideas, ed. S.P. Stich, 1-22. Berkeley: University of California Press.

Sober, Elliott. 1988. Apportioning causal responsibility. Journal of Philosophy 85: 303-318.

Wendler, Dave. 1996. Innateness as an explanatory concept. Biology and Philosophy 11: 89-116.

Wimsatt, William. 1986. Developmental constraints, generative entrenchment and the innate-acquired distinction. In Integrating scientific disciplines, ed. W. Bechtel. Dordrecht: Nijhoff.

Wimsatt, William. 1999. Generative entrenchment, evolution, and innateness: Philosophy, evolutionary biology, and conceptual foundations of science. In Where biology meets psychology: Philosophical essays, ed. V.G. Hardcastle, 185-208. Cambridge, MA: MIT Press.

Waters, Kenneth C. 2007. Causes that make a difference. The Journal of Philosophy 104: 551-579.

Wolf, Ulrich. 1997. Identical mutations and phenotypic variation. Human Genetics 100: 305-321. 